Scientia Agricola

http://dx.doi.org/10.1590/1678-992X-2016-0120

\title{
Milk quality parameters associated with the occurrence of veterinary drug residues in bulk tank milk
}

\author{
Lidia Cristina Almeida Picinin ${ }^{1}$, Isabela Maia Toaldo², Rodrigo Barcellos Hoff ${ }^{3}$, Fernando Nogueira Souza ${ }^{4 *}$, Mônica Oliveira Leite ${ }^{5}$, \\ Leorges Moraes Fonseca ${ }^{5}$, Soraia Araújo Diniz ${ }^{6}$, Marcos Xavier Silva ${ }^{6}$, João Paulo Amaral Haddad ${ }^{6}$, Mônica Maria Oliveira Pinho \\ Cerqueira ${ }^{5}$, Marilde Terezinha Bordignon-Luiz²
}

\author{
${ }^{1}$ State University of Santa Catarina/Center of Agroveterinary \\ Sciences - Dept. of Food and Animal Production, Av. Luiz de \\ Camões, 2090 - 88520-000 - Lages, SC - Brazil. \\ ${ }^{2}$ Federal University of Santa Catarina - Dept. of Food \\ Science and Technology, Rod. Admar Gonzaga, 1346 - \\ 88034-001 - Florianópolis, SC - Brazil. \\ ${ }^{3}$ Ministry of Agriculture, Livestock and Food Supply - \\ National Agricultural Lab., Estr. da Ponta Grossa, 3036 - \\ 91780-580 - Porto Alegre, RS - Brazil. \\ ${ }^{4}$ University of São Paulo/FMVZ - Dept. of Clinical Science, \\ Av. Prof. Dr. Orlando Marques de Paiva, 87 - 05508-270 - \\ São Paulo, SP - Brazil. \\ ${ }^{5}$ Federal University of Minas Gerais/Neterinary School - \\ Dept. of Technology and Inspection of Animal Products, Av. \\ Antônio Carlos, 6627 - 31270-901 - Belo Horizonte, MG \\ - Brazil. \\ ${ }^{6}$ Federal University of Minas Gerais/Neterinary School - \\ Dept. of Preventive Veterinary Medicine. \\ *Corresponding author <nogueirasouza@yahoo.com.br>
}

Edited by: Pedro Esteves Duarte Augusto

Received November 16, 2015

Accepted April 28, 2016
ABSTRACT: Veterinary drug residues in bulk tank milk are important to all sectors of the dairy chain because they are one of the major factors which determine the safety of the final product. This study attempted to identify milk quality parameters that are associated with the occurrence of veterinary drug residues using multivariate principal component analysis (PCA). A total of 132 raw milk samples were collected from 45 dairy farms in the state of Minas Gerais - Brazil and analyzed for 42 analytes, including pyrethroids, macrocyclic lactones and antibacterials, using liquid chromatography coupled with mass spectrometry in tandem mode and gas chromatography with electron capture detection. Out of the 132 milk samples, 40 samples tested positive for at least one analyte (above the detection limit). The milk parameters associated with the antimicrobial residues by confirmatory tests were lactose and nonfat concentrations, as revealed by PCA. This analysis showed that fat and total solid concentrations, as well as the somatic cell and total bacteria counts were associated with macrocyclic lactone residues in bulk tank milk. A PCA assessing pyrethroid residues in bulk tank milk revealed that the lactose and nonfat solid concentrations and titratable acidity were inversely associated with these residues. Thus, the data analysis indicated that the veterinary drug residues were associated with certain milk quality parameters that can be used to target farms at higher risk of veterinary drug residue contamination for testing programs in combination with incentives, education and training programs to improve mammary health, milk hygiene and safety.

Keywords: pesticide, anthelmintic, antibacterial, macrocyclic lactone, food safety

\section{Introduction}

The challenges to provide a food supply that is safe and nutritious are complex since all aspects of food production "from farm to fork" should be considered. Successful milk quality assurance programs start with farm bulk tank milk that is free of veterinary drug residues and has somatic cell counts (SCC) and bacterial counts that are both low resulting in better quality products with longer shelf lives (Ruegg and Tabone, 2000).

Antibacterials, pyrethroids and macrocyclic lactones are the most widely used veterinary drugs in dairy cattle management for both disease therapy and the control of bacterial and parasitic infections (Toaldo et al., 2012). Extensive and improper use of these active compounds can lead to the presence of their residues in milk, risks to human health, the development of microbial drug resistance, the spread of resistant pathogens, and a loss of industrial output and technological problems in dairy production (Ruegg and Tabone, 2000; Toaldo et al., 2012). In this regard, an attempt should be made to identify and interpret the variation of milk quality pa- rameters and the occurrence of veterinary drug residues from an integrated point of view because these variables reflect overall milk quality and management practices (Gonzalo et al., 2010).

Identification of risk factors for discrimination between farms that are at higher risk for veterinary drug residues should allow for the cost-effective targeting of regulatory, educational and consultative resources. Although a number of previous studies have investigated the association between certain milk quality parameters and the occurrence of antimicrobial residues by screening methods (Ruegg and Talbone, 2000; Saville et al., 2000; Van Schaik et al., 2002; Shitandi and Kihumbu, 2004; Gonzalo et al., 2010), more accurate chromatographic methods that are coupled with highly specific and sensible detection systems, such as tandem mass spectrometry, are required to identify and confirm the presence of these compounds (Molina et al., 2003; Samanidou and Nisyriou, 2008; Toaldo et al., 2012). To our knowledge, this is the first study to attempt to identify associations between milk quality parameters and veterinary drug residues detected by confirmatory tests in bulk tank milk. 
We hypothesized that a number of quality parameters could be related to the presence of veterinary drug residues in raw milk. Thus, the present study attempted to identify the milk quality parameters that were associated with the occurrence of veterinary drug residues using multivariate principal component analysis (PCA).

\section{Materials and Methods}

\section{Milk samples}

Raw milk samples were collected from Aug 2009 to Feb 2010 from 45 dairy farms in the state of Minas Gerais, Brazil (Figure 1). A total of 132 samples were collected from bulk milk tanks after milk homogenization. Given the extensive sampling that was required and the analysis cost, dairy herds were randomly selected based on the list of farms from the most important dairy plant in the region by considering their levels of daily milk production. Twenty-seven $(60 \%)$ of the dairy farms had production levels of $\leq 500 \mathrm{~L} \mathrm{~d}^{-1}$, five $(11 \%)$ had production levels of between 501 and $1,000 \mathrm{~L} \mathrm{~d}^{-1}$ and $13(29 \%)>1,000 \mathrm{~L} \mathrm{~d}^{-1}$. Thus, the milk samples that were obtained were representative of the dairy farms belonging to the region of study. In the present study, a milk sample was assumed to be positive if any analytical residue was detected, regardless of the drug concentration. The milk samples were stored frozen at $-18^{\circ} \mathrm{C}$ until the quantitative analysis of veterinary drug residues was carried out.

\section{Milk quality}

Milk quality was assessed by the SCC, milk composition, total bacteria count (TBC) and titratable acidity level. The SCC and milk composition (fat, total protein, lactose, nonfat solid and total solid contents) was analysed using automated equipment (CombSystem 2300, Bentley Instruments, Chaska, USA) from milk samples that were collected in $40 \mathrm{~mL}$ vials containing microtab-

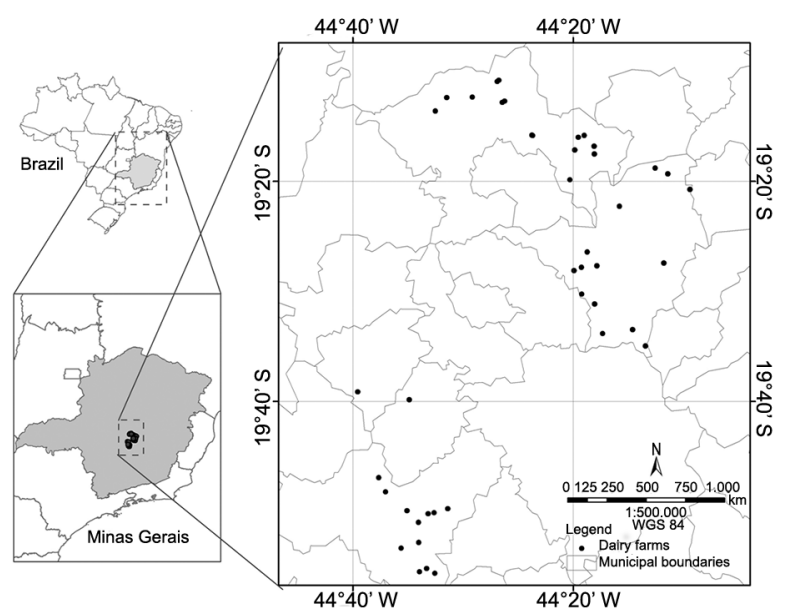

Figure 1 - Spatial distribution of the dairy farmers used in the present study based on their latitude and longitude coordinates. lets of bronopol (2-bromo-2-nitropane-1,3-diol). TBCs were determined with a Bactocount ${ }^{\circledR}$ unit (Bentley Instruments, Chaska, USA) from milk samples that were collected with azidiol $\left(3 \mu \mathrm{L} \mathrm{mL}^{-1}\right)$. Samples for titratable acidity were evaluated using the Dornic method (Tamine and Robinson, 1999). They were collected without any preserving agent and stored at $4{ }^{\circ} \mathrm{C}$ until analysis.

\section{Chemicals and standard solutions}

\section{Pesticides}

The analytical standards $\gamma$-cyhalothrin $(\gamma \mathrm{CYH})$, $\lambda$-cyhalothrin $(\lambda \mathrm{CYH})$, cyfluthrin $(\mathrm{CYF})$, cypermethrin (CYP), deltamethrin (DEL), fenvalerate (FEV) and permethrin (PER), which all possessed levels of $95 \%$ certified purity, were obtained from Sigma-Aldrich (St. Louis, MO, USA). For the pyrethroids, standard stock solutions of $1 \mathrm{mg} \mathrm{mL} \mathrm{mL}^{-1}$ were prepared individually in acetonitrile $(\mathrm{ACN})$ and stored in a refrigerator at $8{ }^{\circ} \mathrm{C}$. Working standard solutions containing all of the pyrethroids were diluted with $\mathrm{ACN}$ to give calibration solutions ranging

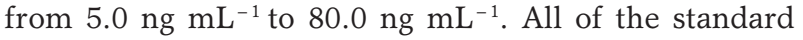
solutions were stored at $-20^{\circ} \mathrm{C}$.

\section{Macrocyclic lactones and antibacterials}

The following analytical standards: penicillin G (PNG), penicillin V (PNV), ceftiofur (CFT), cloxacillin (CLX), dicloxacillin (DCX), oxacillin (OXA), chlortetracycline (CTC), doxycycline (DOX), tetracycline (TC), oxytetracycline (OTC), oxolinic acid (OXO), nalidixic acid (NALIDIX), flumequine (FLU), difloxacin (DIFLO), ciprofloxacin (CIPRO), enrofloxacin (ENRO), norfloxacin (NOR), sarafloxacin (SARA), trimethoprim (TMP), sulfadimethoxine (SDMX), sulfaquinoxaline (SQX), sulfadiazine (SDZ), sulfathiazole (STZ), sulfapyridine (SPY), sulfamethoxazole (SMA), sulfamethazine (SMZ), sulfachloropyridazine (SCP), sulfisoxazole (SFX), sulfadoxine (SDX), sulfamerazine (SMR), ivermectin (IVR), eprinomectin (EPR), emamectin (EMA), doramectin (DOR), abamectin $(\mathrm{ABA})$ and moxidectin $(\mathrm{MOX})$ were purchased from Sigma Aldrich (St. Louis, MO, USA) as Vetranal ${ }^{\mathrm{TM}}$ analytical-grade standards (> $95 \%$ certified purity).

For the $\beta$-lactams, stock standard solutions were prepared by dissolving all of the compounds in polypropylene glycol 3000 in acetate buffer $(\mathrm{pH}=4.5)$ at concentrations ranging from 0.5 to $3.75 \mathrm{mg} \mathrm{mL}^{-1}$. For the tetracyclines, sulfonamides and fluoroquinolones, a stock standard solution of each compound was prepared by dissolving $10 \mathrm{mg}$ of the analytical standard in $10 \mathrm{~mL}$ of the appropriate solvent (acetonitrile for the tetracyclines and sulfonamides, methanol with a couple of drops $(\sim 2)$ of $1 \mathrm{M} \mathrm{NaOH}$ for the fluoroquinolones and methanol for the TMP). Aliquots of each stock solution were diluted to obtain final concentrations of $10 \mu \mathrm{g} \mathrm{mL} \mathrm{m}^{-1}$ and $1 \mu \mathrm{g} \mathrm{mL}^{-1}$, which were then stored at $-20{ }^{\circ} \mathrm{C}$.

For the macrocyclic lactones, individual stock solutions of $1.0 \mathrm{mg} \mathrm{mL}^{-1}$ were prepared by dissolving $10 \mathrm{mg}$ of each standard in $10 \mathrm{~mL}$ of $\mathrm{ACN}$. The working 
solutions were prepared by combining aliquots of each stock solution in ACN to obtain final concentrations of 1 $\mu \mathrm{g} \mathrm{mL} \mathrm{m}^{-1}$ for ABA, IVR and MOX, $1.5 \mu \mathrm{g} \mathrm{mL} \mathrm{m}^{-1}$ for DOR and $2.0 \mu \mathrm{g} \mathrm{mL}^{-1}$ for EPR in ACN. EMA was used as an internal standard, and its working solution was prepared at $1.0 \mu \mathrm{g} \mathrm{mL} \mathrm{mL}^{-1}$ in $\mathrm{ACN}$.

All of the reagents were of analytical grade unless otherwise indicated. Acetic acid, trichloroacetic acid, ACN (MeCN, MS-grade), ethanol and methanol $(\mathrm{MeOH}$, MS-grade) were purchased from Merck (Darmstadt, Germany). Formic acid and triethylamine were supplied by J.T. Baker (Phillipsburg, NJ, USA). Deionized ultra-pure water (< 18.2 M $\Omega \mathrm{cm}$ resistivity) was obtained from the Milli-Q SP Water System (Millipore, Bedford, MA, US). Disodium EDTA ( $\mathrm{Na}_{2}$ EDTA) was obtained from Sigma. Ammonium acetate (analytical grade) was obtained from Mallinckrodt-Baker (Phillipsburg, NJ, USA).

\section{Equipment and chromatographic conditions}

\section{Gas chromatograph with electron capture detector (GC-ECD) for pyrethroids}

The analytical system used for this study was a Trace GC Ultra gas chromatograph (Thermo Fisher Scientific, Milan, Italy) equipped with a splitless injection system, AI 3000 autosampler and ${ }^{63} \mathrm{Ni}$ electron-capture detector fitted with either an OV-5 fused silica capillary column (15.0 m $\times 0.25 \mathrm{~mm} \times 0.1 \mu \mathrm{m}$ film thickness) or an OV-35 fused silica capillary column $(15.0 \mathrm{~m} \times 0.25$ $\mathrm{mm} \times 0.25 \mu \mathrm{m}$ film thickness). The programmed temperature cycle for the OV-5 column was as follows: 100 ${ }^{\circ} \mathrm{C}(1 \mathrm{~min})$ to $250{ }^{\circ} \mathrm{C}$ at a rate of $20{ }^{\circ} \mathrm{C} \mathrm{min}-1$, followed by an increase to $260{ }^{\circ} \mathrm{C}(3 \mathrm{~min})$ at $5^{\circ} \mathrm{C} \mathrm{min}-1$ and finally, to $330^{\circ} \mathrm{C}(5 \mathrm{~min})$ at $20^{\circ} \mathrm{C} \mathrm{min}^{-1}$. The conditions for pyrethroid separation using the OV-35 column were similar to those used for the OV-5 column. The injector and detector were programmed at $240{ }^{\circ} \mathrm{C}$ and $340{ }^{\circ} \mathrm{C}$,

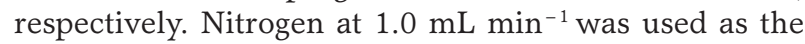
carrier gas. One microliter of each sample was injected in splitless mode. Identification of the peaks was based on comparisons of the retention times of compounds in the standard solutions.

Liquid chromatography coupled with mass spectrometry in tandem mode (LC-MS/MS) multi-residue screening

Prior to the quantitative analysis, an LC-MS/ MS multi-residue screening method was applied to the qualitative analysis of fluoroquinolones, tetracyclines, sulfonamides and trimethoprim in milk. The LC-MS/MS screening analysis was performed using a Waters Alliance 2795 system (Milford, USA) coupled to a Micromass Quattro Micro triple quadrupole mass spectrometer (Waters, Milford, USA) with an electrospray source. The multi-residue separation was performed in a Waters Symmetry C18 LC column (75 mm $\times 4.6 \mathrm{~mm}, 3.5 \mu \mathrm{m})$. A Phenomenex C18 column $(4.0 \mathrm{~mm} \times 3.0 \mathrm{~mm})$ was used as the guard column. A gradient elution program with solvent A (aqueous solution of $0.1 \%$ formic acid) and solvent B (ACN with $0.1 \%$ formic acid) was used. The chromatographic conditions and mass spectrometry parameters were chosen according to Bittencourt et al. (2011). The detection was performed in multiple reaction monitoring mode, and the $2 \mathrm{~m} / \mathrm{z}$ transitions were monitored for each analyte. The $\mathrm{m} / \mathrm{z}$ transitions that were associated with the retention times of the analytes provided confirmatory data, fulfilling the requirements for a confirmatory analysis. For positive results, quantitative methods were applied to determine the analyte concentrations.

\section{LC-MS/MS (macrocyclic lactones and antibacterials)}

The LC system used in this study was an Agilent 1100 series LC (Santa Clara, CA, USA) with a quaternary pump, a vacuum degasser and an autosampler, which was coupled to an API 5000 triple quadrupole mass spectrometer (Applied Biosystems, Foster City, CA, USA) with an electrospray ionization interface. The chromatographic separation of the $\beta$-lactams was performed using a Phenomenex Synergy ${ }^{\circledR}$ C18 analytical column $(150 \times 3.0 \mathrm{~mm}, 4.0 \mu \mathrm{m})$ that was preceded by a security guard C18 column $(4.0 \times 3.0 \mathrm{~mm}, 5 \mu \mathrm{m})$ (Phenomenex). A binary mobile phase was used with a flow of $500 \mu \mathrm{L}$ $\mathrm{min}^{-1}$ for a total run time of $12 \mathrm{~min}$. Mobile phase component $\mathrm{A}$ was an aqueous solution of $0.1 \%$ formic acid, and component B was ACN with $0.1 \%$ formic acid. The detailed chromatographic and mass spectrometry conditions are provided in Jank et al. (2011).

For the tetracyclines, separation was performed on an Xterra C18 column (2.1 mm $\times 100 \mathrm{~mm}, 1.7 \mu \mathrm{m})$ preceded by a security guard C18 column $(4.0 \times 3.0 \mathrm{~mm}$, $5 \mu \mathrm{m})$ (Phenomenex). The mobile phase was applied in gradient mode, using water with $0.05 \%$ formic acid (solvent A) and ACN with $0.05 \%$ formic acid (solvent B).

Separation of the fluoroquinolones was performed on a Waters Symmetry C18 column $(75 \mathrm{~mm} \times 4.6 \mathrm{~mm}$, $3.5 \mu \mathrm{m})$ with a Phenomenex $\mathrm{C} 18(4.0 \mathrm{~mm} \times 3.0 \mathrm{~mm})$ guard column via a gradient elution process, using an aqueous solution of $0.1 \%$ formic acid as solvent $\mathrm{A}$ and $\mathrm{ACN}$ with $0.1 \%$ formic acid as solvent B. For the sulfonamides and trimethoprim, separation was performed on a Zorbax XDB C18 column (150 × $4.6 \mathrm{~mm}, 5 \mu \mathrm{m})$ (Agilent). The mobile phase was composed of $10 \mathrm{mM}$ ammonium acetate that was acidified with $0.01 \%$ acetic acid (solvent A) and methanol (solvent B) using a gradient system. The detailed parameters are described in Hoff et al. (2009).

Separation of the macrocyclic lactones was performed on a Luna C18 column $(150 \mathrm{~mm} \times 2.1 \mathrm{~mm}, 5$ $\mu \mathrm{m})$ that was preceded by a guard column $(4 \mathrm{~mm} \times 3$ $\mathrm{mm}, 5 \mu \mathrm{m}$ ) consisting of the same packing material (Phenomenex, Torrance, CA, USA). All of the analytes were eluted after 4 min using an isocratic mobile phase consisting of $50 \mathrm{mM}$ ammonium acetate buffer ( $\mathrm{pH}$ 5):ACN $(5: 95, \mathrm{v} / \mathrm{v})$ at $0.2 \mathrm{~mL} \mathrm{~min}^{-1}$. The electrospray voltage and source temperature were set at $4500 \mathrm{~V}$ and $500{ }^{\circ} \mathrm{C}$, respectively. 


\section{Sample preparation procedure}

\section{Pyrethroids}

Milk samples $(5.0 \mathrm{~mL})$ were extracted with 10 $\mathrm{mL}$ of $\mathrm{ACN}$ in $50 \mathrm{~mL}$ polypropylene tubes, shaken for $20 \mathrm{~min}$ and then incubated in a freezer at $-20{ }^{\circ} \mathrm{C}$ for approximately $12 \mathrm{~h}$. After this period, the organic phase, which contained an organic solvent with the extracted compounds, remained in liquid form, whereas the aqueous phase and lipidic fraction of the milk froze. The supernatants were passed through previously cooled glass wool containing anhydrous sodium sulfate $(2.0 \mathrm{~g})$. The extracts were concentrated until dry in a water bath (38$40{ }^{\circ} \mathrm{C}$ ) under gentle nitrogen flow. The residues were dissolved in $1.0 \mathrm{~mL}$ of $\mathrm{ACN}$ and analyzed by GC-ECD.

Qualitative determination of fluoroquinolones, tetracyclines, sulfonamides and trimethoprim

Aliquots $(500 \mu \mathrm{L})$ of the raw milk samples were extracted in microcentrifuge tubes $(1.5 \mathrm{~mL})$ by the addition of $20 \mu \mathrm{L}$ of $20 \mathrm{mM}$ EDTA and $200 \mu \mathrm{L}$ of acidified ethanol (3\% acetic acid). The samples were vortexed for approximately $15 \mathrm{~s}$ and then centrifuged at 10,000 g at $5{ }^{\circ} \mathrm{C}$. Aliquots of the supernatants were diluted with water: $\operatorname{ACN}(1: 1, v / v$, both with $0.1 \%$ formic acid) in high-performance liquid chromatography (HPLC) vials and subjected to multi-residue analyses. Ten microliter volumes were injected into the LC-MS/MS system.

\section{Antibacterials}

$\beta$-lactams were determined as described in Jank et al. (2011). The extraction procedure consisted of the sequential addition of $1.0 \mathrm{~mL}$ of $\mathrm{ACN}$ to $2.0 \mathrm{~mL}$ of milk four times, with vortexing between each addition. The sample was then mixed in a head-over-head shaker for $15 \mathrm{~min} ; 1.0 \mathrm{~g}$ of sodium chloride was added, and the sample was mixed in the shaker for an additional 15 min. The samples were centrifuged for $5 \mathrm{~min}$ at 3,000 g at $5{ }^{\circ} \mathrm{C}$. Aliquots of the supernatant were transferred to HPLC vials, and a $10 \mu \mathrm{L}$ volume was injected into the chromatograph.

For the quantitative analysis of tetracyclines, 500 $\mu \mathrm{L}$ of milk was placed in a microcentrifuge tube 12.0 $\mathrm{mL}$ ), and $5 \mu \mathrm{L}$ of $100 \mathrm{mM}$ EDTA was then added. After mixing for 15 s, $200 \mu \mathrm{L}$ of acidified ethanol (3\% acetic acid) was added. The samples were then mixed (15 s) and centrifuged for $10 \mathrm{~min}$ at $12,000 \mathrm{rpm}$ at $5{ }^{\circ} \mathrm{C}$. An aliquot of the supernatant $(350 \mu \mathrm{L})$ was diluted with water $(650 \mu \mathrm{L})$ in an HPLC vial and subjected to LC-MS/ MS analysis.

The quantitative analysis of fluoroquinolones was performed using the same procedure as described above in "Qualitative analysis of fluoroquinolones, tetracyclines, sulfonamides and trimethoprim"; a matrixmatched calibration curve and a specific mass spectrometry method were used for the quantification of fluoroquinolone.

To determine the presence of sulfonamides and trimethoprim, $500 \mu \mathrm{L}$ of milk was vortexed for $15 \mathrm{~s}$ to homogenize, and the analyte extraction was performed with $200 \mu \mathrm{L}$ of acidified ethanol (3\% acetic acid). The extract was mixed for $15 \mathrm{~s}$ and centrifuged for $10 \mathrm{~min}$ at $12,000 \mathrm{rpm}$ at $5{ }^{\circ} \mathrm{C}$. An aliquot of the supernatant $(350$ $\mu \mathrm{L})$ was diluted with water $(650 \mu \mathrm{L})$ in an HPLC vial, and $10 \mu \mathrm{L}$ was injected into the chromatograph for LCMS/MS analysis.

\section{Macrocyclic lactones}

Extraction of the samples was performed as described in Rübensam et al. (2011). For the procedure, 5.0 $\mathrm{mL}$ of milk was extracted with four aliquots of $2.5 \mathrm{~mL}$ of ACN using liquid-liquid extraction with low temperature purification. To this mixture, $2 \mathrm{~g}$ of sodium chloride was added, and the sample was shaken until the salt dissolved. Then, the mixture was centrifuged at $5{ }^{\circ} \mathrm{C}$ for $10 \mathrm{~min}$ at 2,200 $\mathrm{g}$. The top phase was transferred to a $15 \mathrm{~mL}$ polypropylene centrifuge tube and incubated in a freezer for $12 \mathrm{~h}$ at $-20{ }^{\circ} \mathrm{C}$. The remaining liquid phase was then transferred to a new $50 \mathrm{~mL}$ centrifuge tube and evaporated in a water bath $\left(50-55^{\circ} \mathrm{C}\right)$ under a gentle nitrogen flow until completely dry. Finally, the dry extract was reconstituted in $1 \mathrm{~mL}$ of $\mathrm{ACN}$ for further LC-MS/ MS analysis.

\section{Quality assurance and method performance}

All of the samples were subjected to all of the previously described methods. First, the samples were analyzed by a LC-MS/MS screening method for antibacterial residues. For each positive result, a LC-MS/MS quantitative and confirmatory analysis was performed. All of the methods have been fully validated and are currently in routine use in the laboratory network of the Ministry of Agriculture, Livestock and Food Supply of Brazil (MAPA) for the NRCCP (Lins et al., 2012). The results were corrected for recovery. All of the methods applied met the internal criteria for residue analysis.

\section{Statistical analysis}

First, the distribution of all of the variables was examined with normal probability plots using the Kolmogorov and Smirnov tests. To compare the differences between the milk samples with negative and positive results for antibacterial, macrocyclic lactone and pyrethroid residues, an unpaired t-test was used for the data with normal distributions, and the Mann-Whitney Rank test was used for the nonparametric data. All of the SCCs and TBCs were $\log _{10}$-transformed because the distributions were not normal. The significance was set to $p \leq$ 0.05 unless otherwise indicated. The statistical analyses were performed using the GraphPad Prism 5.0 software (GraphPad Software, Inc., San Diego, CA, USA). Furthermore, multidimensional PCA was performed using the STATA statistical software version 12 (Stata Corp., College Station, Texas, USA). To test the associations among all of the variables that were surveyed together, a PCA was performed to assess inferences regarding the pos- 
sible biological meanings underlying the associations between the variables without the pre-establishment of cause/effect. Thus, this statistical technique allows us to graphically visualize the variables in the same dimensional plane and establish relationships between them. The minimum percentage of inertia of the system for the multidimensional PCA was $65 \%$ in relation to the percentage of variance that was explained by the first three axes (components).

\section{Results}

In this study, at least one veterinary drug residue was identified in 40 samples $(30 \%)$ by confirmatory tests (above the detection limit), whereas 16 samples (12 \%) showed the presence of at least two residues. The antibacterial residues in bulk milk tank detected by confirmatory tests were PNV $(\mathrm{n}=1.1 \%), \mathrm{CFT}(\mathrm{n}=7.5 \%)$, OXA $(\mathrm{n}=2.2 \%), \operatorname{DCX}(\mathrm{n}=2.2 \%)$, OTC $(\mathrm{n}=3.2 \%)$, CIPRO ( $\mathrm{n}=3.2 \%)$ and ENRO $(\mathrm{n}=3.2 \%)$. The macrocyclic lactones detected in raw milk were $\mathrm{ABA} / \mathrm{n}=$ $7.5 \%)$, DOR $(\mathrm{n}=3.2 \%)$ and IVR $(\mathrm{n}=10.8 \%)$. The pyrethroid residues detected by GC-ECD in bulk milk tank were CYP $(\mathrm{n}=12.9 \%)$ and DEL $(\mathrm{n}=2.2 \%)$.

The bulk tank milk samples that tested positive for antibacterial residues by confirmatory methods had higher lactose $(p<0.0001)$, total solid $(p=0.004)$, nonfat solid $(p=0.001)$ and fat $(\mathrm{p}=0.05)$ concentrations. Indeed, the milk samples with antibacterial residues showed a tendency toward lower titratable acidity $(p=$ $0.06)$ and lower protein $(p=0.06)$ concentration (Table 1). No difference in milk quality parlameters was observed in the samples with macrocyclic lactone residues, although they tended to have lower titratable acidity $(p$ $=0.07$ ) (Table 1). No difference was observed in the bulk tank milk samples with pyrethroid residues compared to the samples lacking pyrethroid residues (Table 1).

The PCA revealed that the lactose and nonfat solid concentrations were associated with the presence of antibacterial residues in the bulk tank milk (Figure 2A; Table 2). The macrocyclic lactone residues in the bulk tank milk were associated with fat and total solids concentrations, TBC and SCC (Figure 2B; Table 3). The detection of pyrethroid residues in bulk tank milk was inversely associated with titratable acidity levels and lactose and nonfat solid concentrations (Figure 2C; Table 4).

\section{Discussion}

This study identified 12 out of the 42 veterinary drug residues that were under investigation. These data highlight the crucial importance of the role of the dairy industry and government regulatory agencies as monitors of veterinary drug residues in milk combined with incentive, education and training programs in an attempt to reduce the prevalence of excessive veterinary drug residue levels in raw milk.

In this study, higher lactose, total solid, nonfat solid and fat concentrations and the tendency toward higher protein concentrations in the milk samples with antibacterial residues were found. The PCA analysis also confirmed an association between lactose and nonfat solid content with the presence of antibacterial residue in bulk tank milk. One factor that might explain these results could be the management practices and the genetic selection of dairy cattle. The emphasis on maximizing milk production and quality by genetic selection and management practices can lead to increased metabolic demands resulting in oxidative stress. Oxidative stress, especially in high producing animals, is a significant underlying factor in the dysfunctional host immune response, which can increase the susceptibility of dairy cattle to a variety of health disorders (Sordillo and Aitken, 2009) and, as a result, contribute to the use of antimicrobials in dairy farms. In fact, the breeding of cattle for enhanced milk production has been reported to negatively affect health and fertility traits (Veerkamp et al., 2005; Ouweltjes et al., 2007).

In agreement with our results, Shitandi and Kihumbu (2004) in Kenya reported that the California Mastitis Test (239 milk samples from 45 smallholder dairy herds) was not a risk factor for violative antimicrobial residues in milk. On the other hand, some previous studies described that higher bulk milk SCC levels are associated with antibacterial residues violations using screening methods (Ruegg and Tabone, 2000; Saville et al., 2000).

Table 1 - Milk quality parameters of 132 bulk tank milk samples used in the present study.

\begin{tabular}{|c|c|c|c|c|c|c|}
\hline \multirow{2}{*}{ Variables } & \multicolumn{2}{|c|}{ Antimicrobial residues } & \multicolumn{2}{|c|}{ Macrocyclic lactone residues } & \multicolumn{2}{|c|}{ Pyrethroid residues } \\
\hline & Negative $(n=115)$ & Positive $(n=17)$ & Negative $(n=110)$ & Positive $(n=22)$ & Negative ( $\mathrm{n}=118$ ) & Positive $(n=14)$ \\
\hline Titritable acidity $\left({ }^{\circ} \mathrm{D}\right)$ & $16.09( \pm 0.11)^{a}$ & $15.51( \pm 0.22)^{a}$ & $16.09( \pm 0.12)^{a}$ & $15.59( \pm 0.20)^{a}$ & $16.05( \pm 0.11)^{\mathrm{a}}$ & $15.65( \pm 0.21)^{\mathrm{a}}$ \\
\hline Lactose (\%) & $4.67( \pm 0.02)^{b}$ & $4.87( \pm 0.04)^{a}$ & $4.69( \pm 0.02)^{\mathrm{a}}$ & $4.76( \pm 0.04)^{\mathrm{a}}$ & $4.70( \pm 0.02)^{a}$ & $4.69( \pm 0.05)^{a}$ \\
\hline Fat (\%) & $3.61( \pm 0.03)^{b}$ & $3.79( \pm 0.09)^{a}$ & $3.63( \pm 0.04)^{a}$ & $3.63( \pm 0.08)^{a}$ & $3.63( \pm 0.03)^{a}$ & $3.66( \pm 0.10)^{a}$ \\
\hline Protein (\%) & $3.23( \pm 0.01)^{\mathrm{a}}$ & $3.29( \pm 0.03)^{a}$ & $3.24( \pm 0.01)^{a}$ & $3.22( \pm 0.02)^{a}$ & $3.24( \pm 0.01)^{\mathrm{a}}$ & $3.21( \pm 0.04)^{\mathrm{a}}$ \\
\hline Nonfat solids (\%) & $8.77( \pm 0.02)^{b}$ & $8.92( \pm 0.04)^{a}$ & $8.78( \pm 0.02)^{a}$ & $8.80( \pm 0.03)^{\mathrm{a}}$ & $8.79( \pm 0.02)^{\mathrm{a}}$ & $8.75( \pm 0.04)^{a}$ \\
\hline Total solids (\%) & $12.38( \pm 0.04)^{b}$ & $12.71( \pm 0.10)^{a}$ & $2.42( \pm 0.04)^{a}$ & $12.43( \pm 0.09)^{a}$ & $12.42( \pm 0.04)^{\mathrm{a}}$ & $12.42( \pm 0.13)^{\mathrm{a}}$ \\
\hline Log SCC & $5.66( \pm 0.03)^{a}$ & $5.59( \pm 0.10)^{a}$ & $5.64( \pm 0.03)^{a}$ & $5.70( \pm 0.07)^{a}$ & $5.65( \pm 0.03)^{a}$ & $5.67( \pm 0.09)^{a}$ \\
\hline Log TBC & $4.84( \pm 0.08)^{a}$ & $5.11( \pm 0.20)^{a}$ & $4.87( \pm 0.08)^{\mathrm{a}}$ & $4.87( \pm 0.22)^{\mathrm{a}}$ & $4.88( \pm 0.08)^{\mathrm{a}}$ & $4.77( \pm 0.26)^{\mathrm{a}}$ \\
\hline
\end{tabular}

Different superscripted letters within a row indicate significant differences ( $p \leq 0.05$ ) between milk samples with negative and positive results for antimicrobial, macrocyclic lactone or pyrethroid residues. The results are shown as the mean ( \pm SE). SCC = somatic cell count; TBC = total bacteria count. 


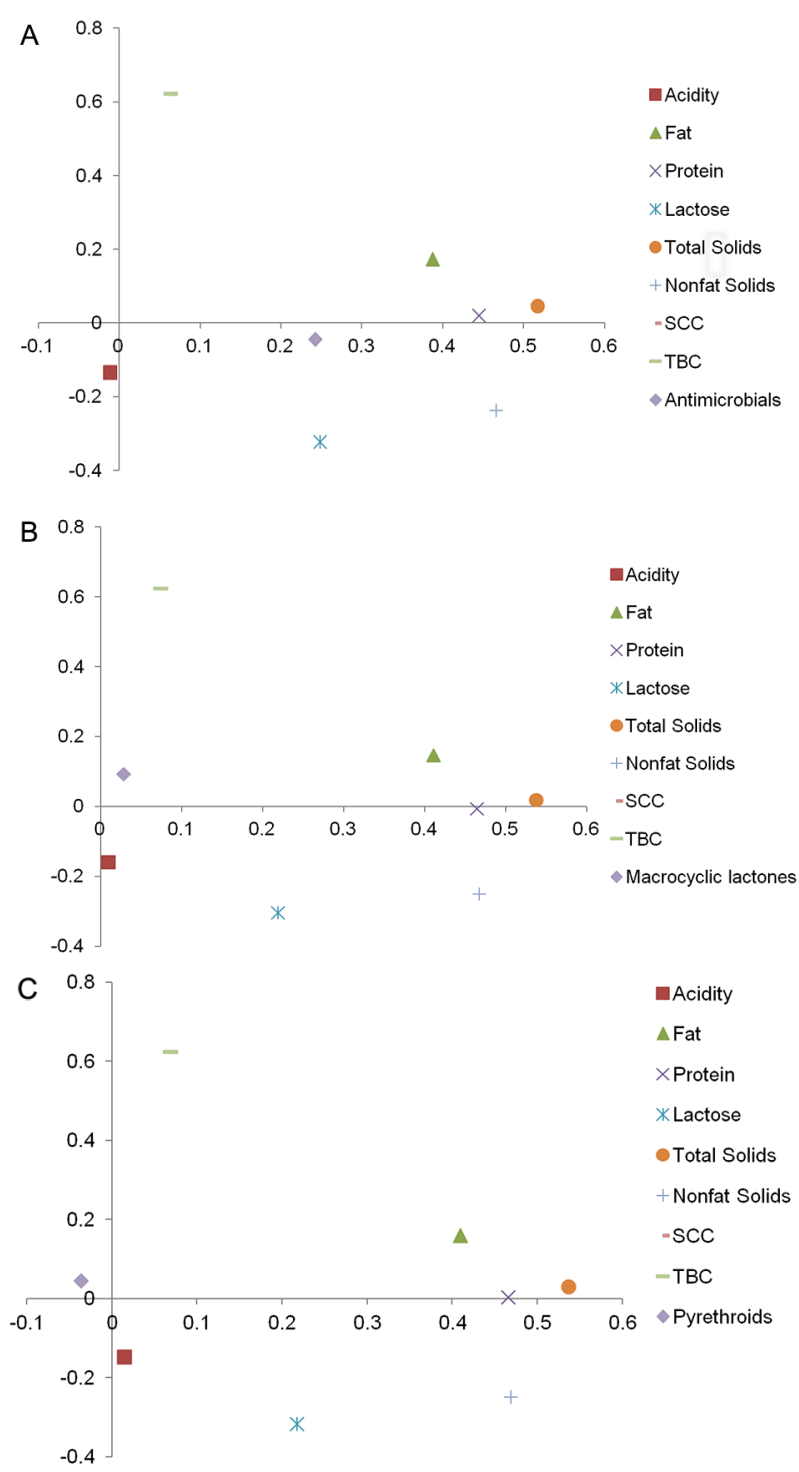

Figure 2 - Plot of the principal multidimensional components analysis (PCA) of antimicrobial (A), macrocyclic lactone (B) and pyrethroid $(C)$ residues by confirmatory methods and their correlations with milk quality parameters (titratable acidity (acidity), protein, fat, lactose, total solid (TS) and nonfat solid (NS) concentrations, somatic cell counts (SCC) and total bacteria counts (TBC)) for components 1 (x axis) and 2 (y axis) of the PCA. The variables in the same quadrant were closely associated, and those in opposite quadrants had opposite effects (components 1 and 2). The variables in other quadrants were regarded as independent variables.

Therefore, the lack of recommendation for the treatment of subclinical mastitis during lactation in dairy cattle in Brazil (Reis et al., 2003; Zafalon et al., 2007) may also explain why the SCC was not associated with antibacterial residues in bulk tank milk in this study. Furthermore, it is possible that the hierarchy of risk factors differs depending on the region and the herds that are under investiga-
Table 2 - The relationship between milk quality variables and antimicrobial residues expressed as loadings in a principal components analysis.

\begin{tabular}{lccc}
\hline \multirow{2}{*}{ Variables } & \multicolumn{3}{c}{ Principal component analysis } \\
\cline { 2 - 4 } & Component 1 & Component 2 & Component 3 \\
\hline Antimicrobial residues & 0.243 & -0.045 & 0.387 \\
Acidity & -0.011 & -0.135 & -0.501 \\
Fat & 0.388 & 0.172 & -0.379 \\
Protein & 0.445 & 0.020 & -0.057 \\
Lactose & 0.248 & -0.323 & 0.513 \\
Total solid & 0.517 & 0.046 & -0.250 \\
Nonfat solid & 0.466 & -0.239 & 0.165 \\
SCC & 0.064 & 0.622 & 0.200 \\
TBC & 0.064 & 0.622 & 0.200 \\
\hline
\end{tabular}

The screen test displayed 3 components. Acidity = titratable acidity; SCC = somatic cell count; TBC $=$ total bacteria count.

Table 3 - The relationship between milk quality variables and macrocyclic lactone residues expressed as loadings in a principal components analysis.

\begin{tabular}{lccc}
\hline \multirow{2}{*}{ Variables } & \multicolumn{3}{c}{ Principal component analysis } \\
\cline { 2 - 4 } & Component 1 & Component 2 & Component 3 \\
\hline Macrocyclic lactone residues & 0.028 & 0.094 & 0.403 \\
Acidity & 0.009 & -0.160 & -0.516 \\
Fat & 0.411 & 0.146 & -0.347 \\
Protein & 0.465 & -0.006 & -0.022 \\
Lactose & 0.219 & -0.304 & 0.567 \\
Total solid & 0.538 & 0.019 & -0.194 \\
Nonfat solid & 0.467 & -0.250 & 0.236 \\
SCC & 0.074 & 0.624 & 0.134 \\
TBC & 0.074 & 0.624 & 0.134 \\
\hline
\end{tabular}

The screen test displayed 3 components. Acidity $=$ titratable acidity; SCC = somatic cell count; TBC $=$ total bacteria count.

Table 4 - The relationship between milk quality variables and pyrethroid residues expressed as loadings in a principal components analysis.

\begin{tabular}{lccc}
\hline \multirow{2}{*}{ Variables } & \multicolumn{3}{c}{ Principal component analysis } \\
\cline { 2 - 4 } & Component 1 & Component 2 & Component 3 \\
\hline Pyrethroid residues & -0.036 & 0.045 & 0.061 \\
Acidity & 0.015 & -0.148 & -0.499 \\
Fat & 0.410 & 0.159 & -0.413 \\
Protein & 0.466 & 0.003 & 0.063 \\
Lactose & 0.218 & -0.318 & 0.579 \\
Total solid & 0.537 & 0.030 & -0.224 \\
Nonfat solid & 0.469 & -0.250 & 0.294 \\
SCC & 0.069 & 0.623 & 0.211 \\
TBC & 0.069 & 0.623 & 0.211 \\
\hline
\end{tabular}

The screen test displayed 3 components. Acidity = titratable acidity; SCC = somatic cell count; TBC $=$ total bacteria count.

tion. For instance, Van Schaik et al. (2002) described that larger farms in the New York State - USA had lower SCC and bacteria counts, but more antibiotic violations.

The PCA showed that the fat and total solid concentrations, the SCC and the TBC were associated with macrocyclic lactone residues in bulk tank milk. Congruently, it has been reported that cows that have been treated with 
anthelmintics have greater milk fat yields than untreated controls (Gross et al., 1999). Further, several infections with non-mastitis pathogens appear to be associated with udder health (Barkema et al., 2009). For instance, the detrimental effects of gastrointestinal nematodes on the immune responses of cows (Gasbarre, 1997) may affect udder health, and consequently increase the SCC (an indicator of mammary gland health) and the TBC, as these milk quality parameters appear to be associated (Pantoja et al., 2009).

The PCA for pyrethroid residues in bulk tank milk revealed an inverse association with lactose and nonfat solid concentrations as well as titratable acidity levels. The months during which the dairy cows experienced increased infestation by insects and ticks, such as horn flies (Haematobia irritans) and Rhipicephalus (Boophilus) microplus, coincided with the time period that the cows primarily remained on the pasture (Estrada-Peña et al., 2006). Because treatment with pyrethroids is mainly based on the subjective observation of infestation levels, treatment of these animals is typically increased (Da Rocha et al., 2012) in months when cows remained on the pasture. A positive relationship between milk lactose and energy balance has been proposed, suggesting that milk lactose concentrations are affected by energy balance (Schei et al., 2005; Beerda et al., 2007; Ouweltjes et al., 2007). Thus, pasture cows, which use energy to walk to and from the grazing padlocks in addition to expending during grazing, most likely expend more energy than confinement-fed cows. This increased energy expenditure could impact their energy balances and, consequently, milk lactose concentrations (Ouweltjes et al., 2007). Collectively, the data regarding the positive relationship between milk lactose and energy balance may explain why lactose concentrations were inversely related to pyrethroid residues (Schei et al., 2005; Beerda et al., 2007; Ouweltjes et al., 2007).

Data analyses indicated that the veterinary drug residues that were detected using the laborious and expensive confirmatory tests were associated with some milk quality parameters that are easy, fast and cheap parameters for dairy plants. Thus, a number of milk quality parameters can be used in a large scale to target farms that are at higher risk for veterinary drug residues for testing programs in combination with incentives, education and training programs to improve mammary health, milk hygiene and safety.

\section{Acknowledgements}

This study was supported by the Brazilian National Council for Scientific and Technological Development (CNPq), Ministry of Agriculture, Livestock and Food Supply (MAPA), and Laboratory of Milk Quality Analysis (LabUFMG) of the Veterinary School from the Federal University of Minas Gerais. We are very grateful to Gabriel Rübensam, Doriane Sacheto, Louise Jank and Magda Targa Martin for their valuable assistance with the chemical analyses.

\section{References}

Barkema, H.W.; Green, M.J.; Bradley, A.J.; Zadokds, R.N. 2009. Invited review: the role of contagious disease in udder health. Journal of Dairy Science 92: 4717-4729.

Beerda, B.; Ouwelties, W.; Sebek, L.B.J.; Windig, J.J.; Veerkamp, R.F. 2007. Effects of genotype by environment interactions on milk yield, energy balance, and protein balance. Journal of Dairy Science 90: 219-228.

Bittencourt, M.S.; Martins, M.T.; Albuquerque, F.G.S.; Barreto, F.; Hoff, R. 2011. High-throughput multiclass screening method for antibacterial residue analysis in meat using liquid chromatography-tandem mass spectrometry: a novel minimum sample preparation procedure. Food Additives and Contaminants A 19: 1-9.

Da Rocha, C.M.B.M.; Bruhn, F.R.P.; Leite, R.C.; Guimarães, A.M.; Sampaio, I.S.; Oliveira, P.R. 2012. Principal component analysis on the perceptions of milk producers about Rhipicephalus (Boophilus) microplus control in Minas Gerais. Revista Brasileira de Parasitologia Veterinária 21: 224-231.

Estrada-Peña, A.; Corson, M.; Venza, J.M.; Mangold, A.J.; Guglielmone, A. 2006. Changes in climate and habitat suitability for the cattle tick Boophilus microplus in its southern Neotropical distribution range. Journal of Vector Ecology 31: 158-167.

Gasbarre, L.C. 1997. Effects of gastrointestinal nematode infection on the ruminant immune system. Veterinary Parasitology 72: 337-342.

Gonzalo, C.; Carriedo, J.A.; Garcia-Jimeno, M.C.; Pérez-Bilbao, M.; de la Fuente, L.F. 2010. Factors influencing variation of bulk milk antibiotic residue occurrence, somatic cell count, and total bacteria count in dairy sheep flocks. Journal of Dairy Science 93: 1587-1595.

Gross, S.J.; Ryan, W.G.; Ploeger, H.W. 1999. Anthelmintic treatment of dairy cows and its effect on milk production. Veterinary Record 144: 581-587.

Hoff, R.B.; Barreto, F.; Kist, T.B.L. 2009. Use of capillary electrophoresis with laser-induced fluorescence detection to screen and liquid chromatography-tandem mass spectrometry to confirm sulfonamide residues: validation according to European Union 2002/657/EC. Journal of Chromotography A 1216: 8254-8261.

Jank, L.; Hoff, R.B.; Tarouco, P.C.; Barreto, F.; Pizzolato, T.M. 2011. $\beta$-lactam antibacterials residues analysis in bovine milk by LC-ESI-MS/MS: a simple and fast liquid-liquid extraction method. Food Additives and Contaminants A 12: 1-11.

Lins, E.S.; Conceição, E.S.; Mauricio, A.Q. 2012. Evolution of a residue laboratory network and the management tools for monitoring its performance. Food Additives and Contaminants A 29: 490-496.

Molina, M.P.; Althaus, R.L.; Balasch, S.; Torres, A.; Peris, C.; Fernandez, N. 2003. Evaluation of screening test for detection of antimicrobial residues in milk. Journal of Dairy Science 86: 1947-1952.

Ouweltjes, W.; Beerda, B.; Windig, J.J.; Calus, M.P.L.; Veerkamp, R.F. 2007. Effects of management and genetics on udder health and milk composition in dairy cows. Journal of Dairy Science 90: $229-238$. 
Pantoja, J.C.F.; Reinemann, D.J.; Ruegg, P.L. 2009. Associations among milk quality indicators in raw milk bulk tank. Journal of Dairy Science 92: 4978-4987.

Reis, S.R.; Silva, N.; Brescia, M.V. 2003. Antibiotic therapy for subclinical mastitis control of lactating cows. Arquivo Brasileiro de Medicina Veterinária e Zootecnia 55: 651-658 (in Portuguese, with abstract in English).

Rübensam, G.; Barreto, F.; Hoff, R.B.; Kist, T.L.; Pizzolato, T.M. 2011. A liquid-liquid extraction procedure followed by a low temperature purification step for the analysis of macrocyclic lactones in milk by liquid chromatography-tandem mass spectrometry and fluorescence detection. Analytica Chimica Acta 705: 24-29.

Ruegg, P.L.; Tabone, T.J. 2000. The relationship between antibiotic residue violations and somatic cell count in Wisconsin dairy herds. Journal of Dairy Science 83: 2805-2809.

Samanidou, V.; Nisyriou, S. 2008. Multi-residue methods for confirmatory determination of antibiotics in milk. Journal of Separation Science 31: 2068-2090.

Saville, W.J.A.; Wittum, T.E.; Smith, K.L. 2000. Association between measures of milk quality and risk of violative antimicrobial residues in grade-A raw milk. Journal of American Veterinary Medical Association 217: 541-545.

Schei, I.; Volden, H.; Baevre, L. 2005. Effects of energy balance and metabolizable protein level on tissue mobilization and milk performance of dairy cows in early lactation. Livestock Production Science 95: 35-47.
Shitandi, A.; Kihumbu, A. 2004. Assessment of the California mastitis test usage in smallholder dairy herds and risk of violative antimicrobial residues. Journal of Veterinary Science 5: 5-9.

Sordillo, L.M.; Aitken, S.L. 2009. Impact of oxidative stress on health and immune function of dairy cattle. Veterinary Immunology and Immunopathology 128: 104-109.

Tamine, A.Y.; Robinson, R.K. 1999. Yoghourt Science and Technology. Woodhead Publishing, Cambridge, UK.

Toaldo, I.M.; Gamba, G.Z.; Picinin, L.A.; Rubensam, G.; Hoff, R.; Bordignon-Luiz, M. 2012. Multiclass analysis of antibacterial residues in milk using RP-liquid chromatography with photodiode array and fluorescence detection and tandem mass spectrometer confirmation. Talanta 15: 616-624.

Van Schaik, G.; Lotem, M.; Schukken, Y.H. 2002. Trends in somatic cell counts, bacterial counts, and antibiotic residue violations in New York State during 1999-2000. Journal of Dairy Science 85: 782-789.

Veerkamp, R.F.; Beerda, B.; Van der Lende, T. 2005. Effects of genetic selection for milk yield on energy balance, levels of hormones, and metabolites in lactating dairy cattle, and possible links to reduced fertility. Livestock Production Science 83: 257-275.

Zafalon, L.F.; Nader Filho, A.; Oliveira, J.V.; Resende, F.D. 2007. Subclinical mastitis caused by Staphylococcus aureus: cost benefit analysis of antibiotic therapy in lactating cows. Arquivo Brasileiro de Medicina Veterinária e Zootecnia 59: 577-585. (in Portuguese, with abstract in English). 